\title{
Glutamate and Aspartate Immunoreactivity in Hypothalamic Presynaptic Axons
}

\author{
Anthony N. van den Pol \\ Section of Neurosurgery, Yale University School of Medicine, New Haven, Connecticut 06510
}

Within the hypothalamus, a large number of neuroactive substances are found, many first detected in this part of the brain. Excitatory amino acids, recognized as important transmitters in other parts of the brain, have received little attention here. To study glutamate immunoreactivity at the ultrastructural level in the hypothalamus, postembedding colloidal gold or silver-intensified gold was used. Antisera raised against glutamate conjugated with glutaraldehyde to keyhole limpet hemocyanin were specific for glutamate, tested with a battery of tests including immunodot blot, ELISA assays, Western blot, and Sepharose epoxy-conjugated amino acids. Antisera did not cross-react with other amino acids and related compounds, with proteins containing glutamate, or with polyglutamate.

A population of presynaptic boutons in the suprachiasmatic, arcuate, ventromedial, supraoptic, and parvocellular and magnocellular paraventricular nuclei showed strong immunoreactivity for glutamate. Highly labeled presynaptic axons generally made asymmetrical Gray type 1 synaptic contacts with dendrites or cell bodies and had up to eight times more immunogold particles per unit area than postsynaptic dendrites. Axon terminals exhibiting strong glutamate immunoreactivity had large numbers of round, clear vesicles adjacent to the synaptic specialization together with a few larger, dense-core vesicles. The largest number of gold particles over axons were located in regions containing the small clear vesicles. Axons in general had about three times more gold particles over them than did the postsynaptic dendrites. Staining of single boutons in adjacent serial ultrathin sections with glutamate or GABA antisera showed that non-GABAergic terminals had a higher level of glutamate staining than did axons immunoreactive for GABA. In control experiments, immunostaining with glutamate antiserum could be blocked by solid-phase absorption of the antiserum with glutamate conjugated with glutaraldehyde to proteins.

Aspartate was also detected with immunocytochemistry in some presynaptic boutons in the medial hypothalamus. To compare the response of neurons to aspartate and glutamate, calcium-imaging dyes were used in combination with

\footnotetext{
Received Sept. 25, 1990; revised Jan. 29, 1991; accepted Feb. 8, 1991.

I thank Ms. A. Schneider for excellent histological assistance and Drs. R. Vogt, C. Decavel, and S. Finkbeiner for immunoblotting, staining, and video analysis suggestions. This work was supported by NIH Grants NS 10174 and NS 16296 and by the Air Force Office of Scientific Research.

Correspondence should be addressed to A. N. van den Pol, Section of Neurosurgery, Yale University School of Medicine, 333 Cedar Street, New Haven, CT 06510 .

Copyright (C) 1991 Society for Neuroscience $0270-6474 / 91 / 112087-15 \$ 03.00 / 0$
}

digital video microscopy. Whereas almost all neurons showed a rise in intracellular $\mathrm{Ca}^{2+}$ in response to glutamate, many but not all of the same cells also showed a $\mathrm{Ca}^{2+}$ rise of smaller magnitude in response to aspartate.

These ultrastructural immunocytochemical data, taken in conjunction with biochemical and electrophysiological experiments, suggest that glutamate, and to a lesser extent aspartate, may play an important neurotransmitter role in a wide variety of hypothalamic circuits.

While much previous cytochemical work in the hypothalamus has concentrated on neuroactive peptides and other neurotransmitters, little has focused on excitatory amino acids (Poulain and Wakerly, 1982; Silverman and Pickard, 1983; Swanson and Sawchenko, 1983; Renaud et al., 1985; Renaud, 1987; Sladek and Armstrong, 1987; Swanson, 1987; Hokfelt et al., 1989; Ganong and Martini, 1990). In other areas of the brain where neurons have been reported to utilize an amino acid as a neurotransmitter, high levels of that amino acid are found in the presynaptic axon terminals (Storm-Mathisen et al., 1983; Ottersen and Storm-Mathisen, 1984; van den Pol, 1985; Somogyi et al., 1986; van den Pol and Gorcs, 1988). The present article employs extensively charactcrized antiserum against glutamate to study the ultrastructural distribution of hypothalamic presynaptic axonal endings that contain high concentrations of immunoreactive glutamate. The antibody used binds to glutamate fixed with glutaraldehyde, but not to glutamate when it is part of the normal amino acid structure of proteins or peptides. These studies are based on postembedding immunogold staining, which allows better ultrastructural preservation than preembedding immunostaining and facilitates a semiquantitative comparison of the intensity of immunolabeling over different ultrastructural profiles.

Glutamate has been suggested as the major excitatory amino acid neurotransmitter in a number of neural loci including the hippocampus, cortex, spinal cord, and cerebellum (Curtis and Johnston, 1974; Storm-Mathisen et al., 1983; Taxt and StormMathisen, 1984; Somogyi et al., 1986; Conti et al., 1987) and may be the primary agent in fast excitatory neurotransmission throughout the CNS (Iversen, 1984). Glutamate is taken up into axon terminals in slices and synaptosomes and can be released in a calcium-dependent manner by electrical stimulation or high potassium (De Belleroche and Bradford, 1972; Mulder and Snyder, 1974; Vargas et al., 1977; Nicholls and Sihra, 1986). Its role as the primary excitatory neurotransmitter of motorneurons at neuromuscular junctions in some invertebrates is well established (Atwood, 1976; Bicker et al., 1988). A growing body of physiological evidence suggests that, as in other regions of the brain (Curtis and Johnston, 1974), hypothalamic cells respond 
to glutamate (Moss et al., 1972; Bioulac et al., 1978; Arnauld et al., 1983) and are activated by glutamate agonists, and the postsynaptic responses of most hypothalamic neuroendocrine neurons can be blocked by glutamatc antagonists (Gribkoff and Dudek, 1988; van den Pol et al., 1990). The present study seeks to localize high concentrations of excitatory amino acids, particularly glutamate, in presynaptic hypothalamic axons.

\section{Materials and Methods}

\section{Antibody production}

Prior to use as an antigen, the purity of glutamate was tested by highperformance liquid chromatography and was found to exhibit a high degree of purity. Glutamate was conjugated with glutaraldehyde to keyhole limpet hemocyanin (KLH). Free glutamate and free glutaraldehyde were removed by dialysis in several changes of phosphate buffer.

The glutamate-glutaraldehyde-KLH antigen complex was mixed with complete Freund's adjuvant and injected both sub-and intracutaneously into the backs of several albino rabbits. After 5 weeks, a boost was given with the same antigen in incomplete Freund's adjuvant.

Sera were tested with glutamate conjugated with glutaraldehyde to bovine serum albumin (BSA) on nitrocellulose; staining of glutamate was compared with staining of GABA, aspartate, glycine, and glutamine. The serum with the greatest titer and least cross-reactivity (GLU-2) was used for further analysis, affinity purification, and immunocytochemical staining.

Affinity purification. Raw glutamate antiserum showed a slight crossreaction on nitrocellulose with aspartate and a weaker cross-reaction with glutamine. To reduce this cross-reaction, BSA was coupled to cyanogen bromide activated Sepharose 4B, treated with glutaraldehyde, and conjugated to aspartate, glutamine, GABA, and glycine. Any remaining glutaraldehyde binding sites were saturated with lysine and ethanolamine. Glutamine antiserum was run down a column of BSA conjugated with glutaraldehyde to these heterologous amino acids to remove cross-reacting antibodies.

\section{Glutamate antiserum specificity}

Nitrocellulose dot blots. Three approaches to antigen blots on nitrocellulose were used. The first required amino acids to be independently conjugated to BSA with glutaraldehyde; the resultant complexes were spotted on nitrocellulose and stained with the glutamate antisera using biotinylated goat anti-rabbit IgG followed by avidin-biotin-peroxidase complexes (ABC method of Hsu et al., 1981) used at half the concentrations recommended by the supplier (Vector Labs). Rabbit antiserum against aspartate (gift of Dr. T. Gorcs) was tested in a similar manner. Specificity was also tested with glutaraldehyde-activated polylysine nitrocellulose onto which spots of amino acids could be placed as described by Hodgson et al. (1985).

Immunodot blots were also tested with the peroxidase anti-peroxidase (PAP) procedure of Sternberger (1986). Glutamate was bound with glutaraldehyde to bovine serum albumin. Other putative neuroactive amino acids were also used to test cross-reactivity; these included aspartate, GABA, glycine, and taurine. Equimolar concentrations of the substances were blotted on nitrocellulose with a pore size of $0.22 \mu \mathrm{m}$ using a Biorad 96-well dot-blot apparatus. Nitrocellulose was then treated overnight with $5 \%$ milk and $1 \%$ lysine to reduce nonspecific immunoglobulin sticking. Nitrocellulose strips were incubated in the glutamate antiserum at a 1:2000 dilution for $2 \mathrm{hr}$, washed with phosphate buffer, incubated in secondary goat anti-rabbit immunoglobulin for $45 \mathrm{~min}$, washed, and incubated in rabbit peroxidase anti-peroxidase. Nitrocellulose strips were then incubated in diaminobenzidine with hydrogen peroxide.

ELISA tests for cross-reactivity. To quantify further the potential crossreactions of the antiserum, a test was applied allowing use of spectrophotometry of 96-well plastic plates. Ninety-six-well plates (Dynatech Immulon) were used to allow simultaneous comparison of a large number of different substances and repetitive samples of a single substance. Different amino acids conjugated by glutaraldehyde to bovine serum albumin (BSA) were adsorbed to 96-well plastic plates. Glutamate antiserum was used at dilutions of $1: 1000$ in a buffer containing $0.2 \%$ Triton X-100, $1.5 \%$ sodium chloride, $0.1 \%$ BSA, and $0.05 \mathrm{M}$ Tris. Primary antiserum was detected with affinity-purified goat anti-rabbit immunoglobulin (Flow Labs) conjugated to horseradish peroxidase, fol- lowed by visualization with orthophenaline diamine (OPD), as described in detail elsewhere (van den Pol and Gorcs, 1988).

To determine the density of the OPD reaction product, optical absorbance at $492 \mathrm{~nm}$ was measured with a BioRad EIA 96-well reader interfaced with a lab microcomputer.

Western blots. To test whether the glutamate antibody bound to any other protein from the hypothalamus, or to any other glutaraldehydetreated protein, Western blots of extracted hypothalamic protein were used. Identical $1-\mathrm{cm}$ strips of nitrocellulose were cut from a wide Western blot and prepared under the following conditions: (1) glutamate plus glutaraldehyde, (2) glutaraldehyde alone, (3) GABA plus glutaraldehyde, (4) no glutaraldehyde (the first four lanes were all stained with the primary glutamate antibody GLU-2), (5) GABA plus glutaraldehyde (stained with GABA antibody), and (6) glutamate plus glutaraldehyde (stained with second glutamate antibody).

Strips were stained with the PAP method as described above for the immunodot blot specificity test. Diaminobenzidine or nickel-intensified diaminobenzidine was used to detect reactivity.

Sepharose beads. The amino end of glutamate or GABA was conjugated by a long-carbon-chain epoxy linker to Sepharose beads. Beads were immunostained with either glutamate antiserum or GABA antiserum (Incstar), followed by fluorescein-conjugated secondary goat antirabbit immunoglobulin antiserum.

\section{Postembedding immunocytochemistry}

Rats were heavily anesthetized with Nembutal and perfused transcardially with physiological saline, followed by $3 \%$ glutaraldehyde in 0.1 M phosphate buffer. After $3 \mathrm{hr}$ of postfixation, $75-\mu \mathrm{m}$-thick sections were cut on a Vibratome, treated with $1 \%$ osmium tetroxide for $45 \mathrm{~min}$, and $1 \%$ uranyl acetate for $30 \mathrm{~min}$, and embedded in Araldite. Ultrathin pale gold sections were cut on a Reichert Ultracut microtome and picked up on Formvar-coated and carbon-stabilized nickel or gold grids.

Postembedding staining with $10-\mathrm{nm}$ colloidal gold (Janssen Pharmaceutical) was performed as we have previously described (van den Pol, 1984, 1985; van den Pol and Gorcs, 1988; van den Pol and Decavel, $1990)$. Briefly, either sections were incubated overnight in the primary antiserum (1:3000 to $1: 10,000)$, followed by several washes, and then by $10-\mathrm{nm}$ colloidal gold (1:75) adsorbed to goat anti-rabbit immunoglobulin (Janssen Pharmaceutical), or sections were treated with sodium metaperiodate for $12 \mathrm{~min}$, primary antiserum $(1: 3000$ to $1: 6000)$ for 2 $\mathrm{hr}$, and then with colloidal gold. All staining was done at room temperature in a humidified environment.

Silver-intensified gold. To increase the size and visibility of the metallic particles after immunolabeling on ultrathin sections, some grids were placed in a silver physical developer described in detail elsewhere (Liesegang, 1911; Danscher, 1981; Holgate et al., 1983; van den Pol, $1985,1986 \mathrm{~b}$ ) or in the physical developer from Janssen Pharmaceutical. Grids were placed on drops of silver solution for 3-4 $\mathrm{min}$, and then washed in distilled deionized water several times (van den Pol, 1989).

Serial ultrathin section staining with different antisera. To study single axonal boutons stained with GABA or glutamate antisera, serial ultrathin sections were cut from the magnocellular region of the paraventricular nucleus and picked up on different gold grids. Alternate sections were stained for glutamate or for GABA with the colloidal gold procedures described above. The GABA antiserum has been tested with immunodot blot and shows no cross-reaction with glutamate.

Digital imaging of calcium. To examine the response of hypothalamic neurons to glutamate and aspartate, hypothalamic neurons from fetal rats (embryonic days 17-21) were grown on glass coverslips coated with polylysine. Ten days after plating, cells were loaded with the calciumsensitive dyes fluo-3 acetoxymethylester or calcium green acetoxymethylester (Molecular Probes) and studied with digital video microscopy as described elsewhere (Cornell-Bell et al., 1990; van den Pol et al., 1990). Experiments examining the responses to glutamate, NMDA, and aspartate were done with a HEPES buffer $(10 \mathrm{~mm}$ HEPES, $25 \mathrm{~mm}$ glucose, $3 \mathrm{~mm}$ calcium chloride, $137 \mathrm{~mm}$ sodium chloride, $5.3 \mathrm{~mm}$ potassium chloride, $5 \mathrm{~mm}$ glycine). Neurons were grown in higher densities than we previously used (van den Pol et al., 1990) in minimal essential medium (Gibco) without added glutamine. A Hamamatsu 2400 SIT video camera was interfaced with an Imaging Technology Inc. 151 video processor and an IBM AT microcomputer. A computer-controlled shutter kept the cells in darkness except during the times when video frames were being recorded. 
GLUTAMATE AB

ASPARTATE AB

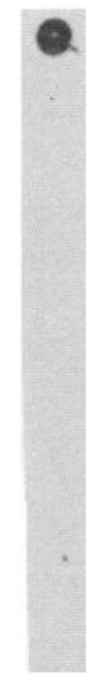

GLU

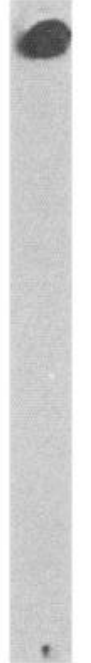

AsP

TAU

GABA

GLU

Asp

GiY

IAU

GIY

GABA

BSA (NO GA)

CYS

BSA

GA

BSN IBG

Figure 1. Different amino acids were conjugated with glutaraldehyde to BSA and applied in 2- $\mu \mathrm{l}$ quantities to nitrocellulose strips. Glutamate antiserum stained only the glutamate-containing spot and did not stain other amino acids linked to the same carrier protein. Similarly, aspartate antibody stained only the aspartate-containing spot. $G A$, glutaraldehyde; $B S A$, bovine serum albumin; $T B G$, thyroglobulin.

\section{Results}

\section{Antiserum characterization}

Immunoblot blot. With the dot blot test for cross-reactivity, only the spot containing glutamate bound with glutaraldehyde to BSA gave a strong positive reaction. No appreciable reaction was detected with the same protein carrier bound with glutaraldehyde to aspartate, GABA, glycine, taurine, native BSA, or glutaraldehyde activated BSA (Fig. 1). The antiserum did not bind to the dipeptide aspartyl glutamate. Lysine was used to block activated glutaraldehyde binding sites, and reactivity with this amino acid was not seen. A different antibody against aspartate reacted only with the aspartate-containing spot (Fig. 1).

Western blots. The tests for specificity with the glutamate antiserum on the Western blots (Fig. 2) control for several factors. This antiserum did not bind to any detectable protein in its native state or after glutaraldehyde cross-linking. It also did not bind to a different neurotransmitter amino acid (GABA) conjugated with glutaraldehyde to any detectable protein. As expected, the antiserum bound to hundreds of different proteins of different molecular weights that had been treated with glutaraldehyde and glutamate.

ELISA analysis. The ELISA-type assay allowed a quantitative assessment of possible cross-reactivity of the glutamate antiserum. A number of substances were tested for possible crossreactivity. Percentage of cross-reactivity was determined by comparison of the absorbance of $0.1 \mathrm{~m}$ of the substance being tested with the absorbance of different concentrations of glutamate standards tested at the same time, as described in more detail for glycine antisera (van den Pol and Gorcs, 1988). No significant cross-reaction was found with any of the primary amino acid neurotransmitter candidates, including GABA, glycine, or aspartate, nor with any other amino acid or compound

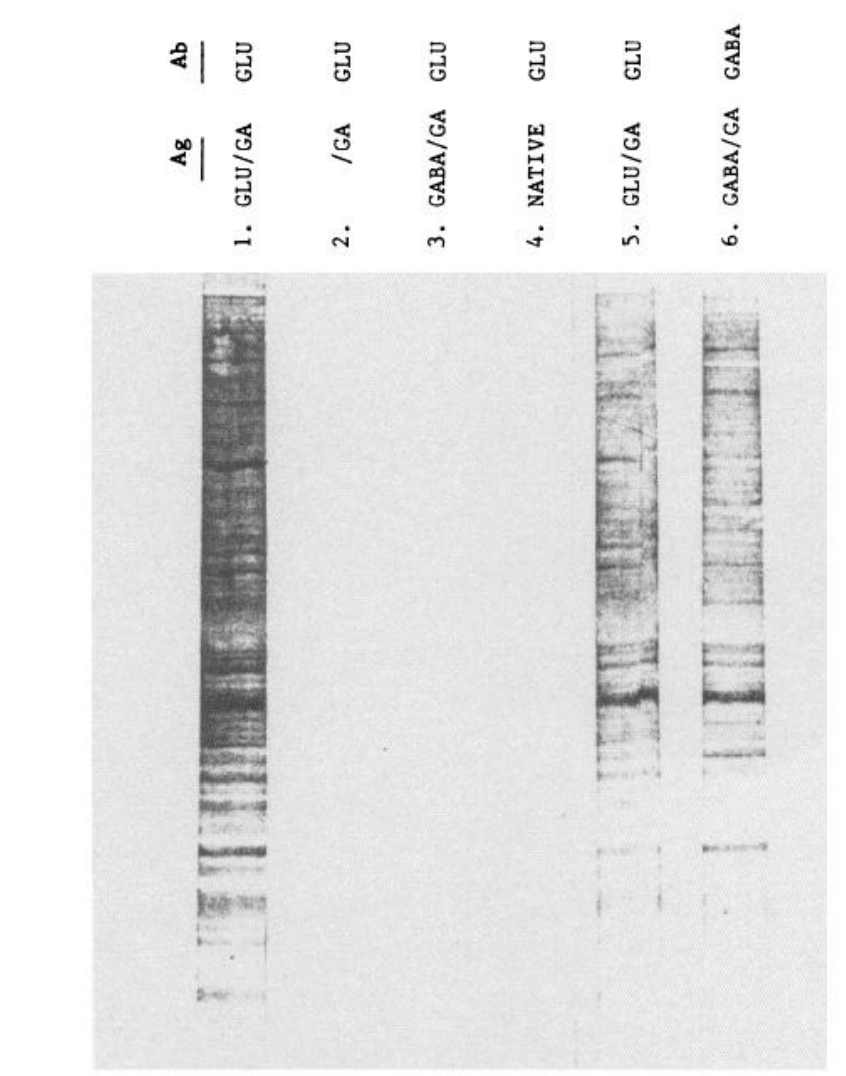

Figure 2. Western blots of hypothalamic protein. The lane on the left shows the glutamate antibody bound to a large number of proteins of different molecular weights fixed with glutaraldehyde $(G A)$ and bound with glutamate $(G L U)$. The second lane shows the glutamate antibody did not bind to proteins fixed with glutaraldehyde in the absence of glutamate, to proteins fixed with glutaraldehyde and bound to GABA (lane 3), or to native unfixed proteins (lane 4). Lane 5 shows that a different glutamate antiserum (from Dr. T. Gorcs) reacts to proteins fixed with glutaraldehyde and bound to glutamate. Lane 6 shows the GABA antibody (Incstar) with a similar pattern of binding to lanes 1 and 5. $A g$, antigen; $A b$, antibody.

(Table 1). A slight cross-reactivity with D-glutamate $(2.9 \%)$ was detected; because D-glutamate is not found in any quantity in the brain, this should not pose a problem. A general level of binding in the $0.1-0.3 \%$ range was found for most glutaraldehyde-conjugated amino acids.

Fixation dependency. To determine if the glutamate recognition was dependent on the glutaraldehyde fixative, several other conjugation procedures were tried. As expected, $10 \%$ paraformaldehyde substituted for $10 \%$ glutaraldehyde did not bind sufficient glutamate and was not detected by the antibody. On the other hand, $10 \%$ acrolein substituted for $10 \%$ glutaraldehyde bound glutamate, and the glutamate antiserum discriminated glutamate-acrolein-BSA from other amino acids bound similarly with acrolein and BSA; the binding affinity for acroleinconjugated glutamate was only a small fraction of that for glutaraldehyde-conjugated glutamate (Table 1). The glutamate antiserum did not bind to glycine, GABA, or aspartate conjugated by acrolein.

Sepharose beads. The glutamate antiserum bound only to the glutamate-epoxy Sepharose, and not to the GABA-epoxy Sepharose (Fig. 3). That the GABA conjugation had been suc- 
Table 1. Cross-reactivity of affinity-purified glutamate antiserum

Amino acid

Cross-reactivity

Alanine
$\beta$-Alanine
D-Aspartate
L-Aspartate
Carnosine
Cysteine
Ethanolamine
GABA
D-Glutamate
L-Glutamate
(Acetyl-)glutamate
Glutaminc
(Acetyl-)glutamine
Glycine
(Acetyl-)glycine
Homo-carnosine
Lysine
Methionine
Phenylalanine
Proline
Serine
Taurine
Tris
Tryptophan
Valine
Polyamino acids
Poly-aspartate
Poly-glutamate
Poly-glycine
Peptides
Aspartate-glycine
Glutamate-alanine
Glycine-glycine-valine
Glutamatamate (paraformate (acrolein conjugation)
Gacrolein conjugation)
Ging conjugation)

Baseline cross-reactivity was $0-0.3 \%$ unless otherwise indicated.

cessful was indicated by positive immunostaining of the GABAconjugated Sepharose with GABA antiserum.

\section{Immunocytochemical staining}

In all hypothalamic nuclei studied, including the magnocellular and parvocellular paraventricular (see Figs. $4 A, B ; 7$ ), ventromedial (Fig. 4C), supraoptic (Fig. $5 A$ ), arcuate (Fig. $5 B$ ), and suprachiasmatic (Fig. 6) nuclei, and throughout the lateral hypothalamic area, glutamate-immunoreactive axon terminals were found making synaptic contact with dendrites and neuronal perikarya. Presynaptic axonal endings that had the strongest labeling with immunogold particles generally had asymmetrical Gray type 1 synaptic specializations (Figs. 4, 5). Small, clear, round vesicles with a diameter of about $45-50 \mathrm{~nm}$ were found in the axon, often clustered near the point of synaptic contact. The highest level of gold labeling per unit area was in regions containing synaptic vesicles (Figs. 4-7). Mitochondria generally had a higher lcvel of gold labeling in immunoreactive presynaptic axons than found in mitochondria in the postsynaptic dendrite. The level of label in astrocytic processes was consistently very low.

Medium-size dense-core vesicles with a diameter of about 60 $\mathrm{nm}$ were often found in axonal endings filled with small, clear vesicles that were immunoreactive for glutamate in all the regions studied, as shown in an example from the paraventricular nucleus (Fig. $4 B$ ). While the small, clear vesicles were often tightly apposed to the presynaptic side of the synaptic membrane specialization, dense-core vesicles were found farther back or lateral to the membrane specialization. While single thin sections did not always reveal dense-core vesicles in axonal endings, serial sections through boutons generally showed some dense-core vesicles in each bouton.

To determine the identity of the neuropil elements with the greatest glutamate immunoreactivity, 30 micrographs with a final magnification of $60,000 \times$ were studied in the paraventricular nucleus. To reduce the probability of focusing on metabolic glutamate, cell bodies and their proximal dendrites that might use glutamate for protein synthesis or for other perikaryal metabolic processes were excluded from this analysis. In 28 of 30 electron micrographs, from over 500 neuropil profiles including axons, dendrites, dendritic spines, and glial processes, axon terminals showed the highest level of glutamate immunoreactivity.

Because axons in general showed a variable level of immunoreactivity, single boutons on serial sections were stained for either GABA or glutamate to determine if axons with low levels of glutamate were GABAergic; glutamate in GABAergic neurons is needed for the enzyme glutamate decarboxylase to synthesize GABA. Axons that showed the most intense staining with glutamate antisera (Fig. 7A) generally did not stain for GABA (Fig. 7B), while axons that were clearly GABA immunoreactive (Fig. 7C) showed a lower level of staining for glutamate (Fig. $7 D$ ). In a comparison of serial sections through 27 boutons stained alternately for GABA or glutamate using a stereological approach described elsewhere (Somogyi et al., 1986; Ottersen, 1989; Decavel and van den Pol, 1990), those boutons that were not GABA immunoreactive (mean, 1 particle) showed a mean of $23.6 \pm 2.2( \pm \mathrm{SEM})$ particles $/ \mu \mathrm{m}^{2}$ after glutamate staining, while those immunoreactive for GABA (mean, 23 particles) showed less (mean, $13.6 \pm 2.8$ particles $/ \mu \mathrm{m}^{2}$ ) glutamate immunoreactivity. The difference in the intensity of labeling for glutamate in GABAergic and non-GABAergic axons was statistically significant $(p<0.05)$, with GABA-immunoreactive terminals showing $74 \%$ fewer particles.

To compare the intensity of immunostaining in axons and dendrites, the number of gold particles per unit area was counted. Twenty axons from the paraventricular nucleus had a mean of $10.7 \pm 2.6$ gold particles compared to their postsynaptic dendrites of $3.5 \pm 0.8$ for the same area. By paired $t$ test the difference was statistically significant ( $p<0.01$ ). Of 20 axodendritic synapses, 18 had a larger number of gold particles in the presynaptic axon than in the postsynaptic dendrite, one had an equal number, and one had a more strongly labeled dendrite. In these comparisons, axons were used irrespective of the type of synaptic specialization they made. Some axons making asymmetrical synaptic specializations had up to eight times more 
gold particles per unit area than their postsynaptic dendrite and were the most immunoreactive structures found in the neuropil.

Whereas the primary focus of the present article is on glutamate, aspartate is another possible excitatory amino acid transmitter. Immunostaining with aspartate antisera in the paraventricular and arcuate nuclei showed strong staining in some axons, and little or no staining in others (Fig. 8). Some neuronal perikarya and proximal dendrites also showed aspartate immunoreactivity (Fig. 8).

\section{Calcium response to aspartate and glutamate}

Under the culture conditions used in the present experiment, many neurons responded to aspartate with a dose-dependent increase in intracellular $\mathrm{Ca}^{2+}$ (Fig. 9). Neurons showed a greater response to glutamate than to an equimolar concentration of aspartate (Fig. 9), regardless of the serial order of amino acid perfusion. Cells that responded to 10 and $100 \mu \mathrm{M}$ aspartate also responded to 10 and $100 \mu \mathrm{M}$ NMDA (Fig. 9, cells TL1-3). Some cells showed little or no response to aspartate or NMDA, but did show an intracellular $\mathrm{Ca}^{2+}$ rise in response to $10 \mu \mathrm{M}$ glutamate (cells TL4, TL6). In most cells, the intracellular $\mathrm{Ca}^{2+}$ rise was followed by a fall after removal of the transmitter or agonist (cells TL1-4, TL6). However, a few cells (e.g., cell TL5) showed an increase in intracellular $\mathrm{Ca}^{2+}$ rise in response to aspartate, which stayed elevated throughout the time course of the experiment.

\section{Perikaryal immunostaining}

Neuron perikarya showed greater immunoreactivity than adjacent glia in the same section (Fig. 10). In the arcuate nucleus, counts of silver-intensified gold particles showed that glial cells had a mean of $6.7 \pm 0.8$ particles $/ \mu \mathrm{m}^{2}$ while neurons had 20.3 \pm 0.7 particles $/ \mu \mathrm{m}^{2}$ over the same area, a statistically greater number $(t$ test; $t=13.7 ; \mathrm{df}=22 ; p<0.001$ ). Similarly, neurons in the paraventricular nucleus showed a stronger immunoreactivity than nearby glial cells, as reported in the magnocellular supraoptic nucleus (Meeker et al., 1989). Neuronal perikarya throughout the hypothalamus have a higher level of labeling than found in the neuropil in general. The density of immunogold staining over perikarya varied with cell type; cell bodies of magnocellular neurosecretory neurons were more strongly labeled than other cells of the medial hypothalamus.

\section{Control immunostaining in hypothalamus}

After absorption of the respective homologous antiserum with glutamate or aspartate conjugated by glutaraldehyde to bovine serum albumin, only background nonspecific labeling was observed. Absorption with GABA conjugated to bovine serum albumin did not block staining with glutamate antiserum. Postembedding control immunostaining with GABA antisera on the same sections labeled only a subset of axons that made symmetrical synapses as described before (van den Pol, 1985, 1986a, 1989) and, in general, did not stain axons that made asymmetrical synaptic junctions. Postembedding staining with peptide antisera against neurophysin or luteinizing hormonereleasing hormone stained only granules in a small population of axons and did not give the staining patterns seen with postembedding immunogold studies with amino acid antisera.

Silver intensification of gold facilitated detection of the particles (Fig. 4). Control grids intensified in silver physical developer but not immunolabeled with gold showed no labeling with the development times used here. Extended incubation of grids
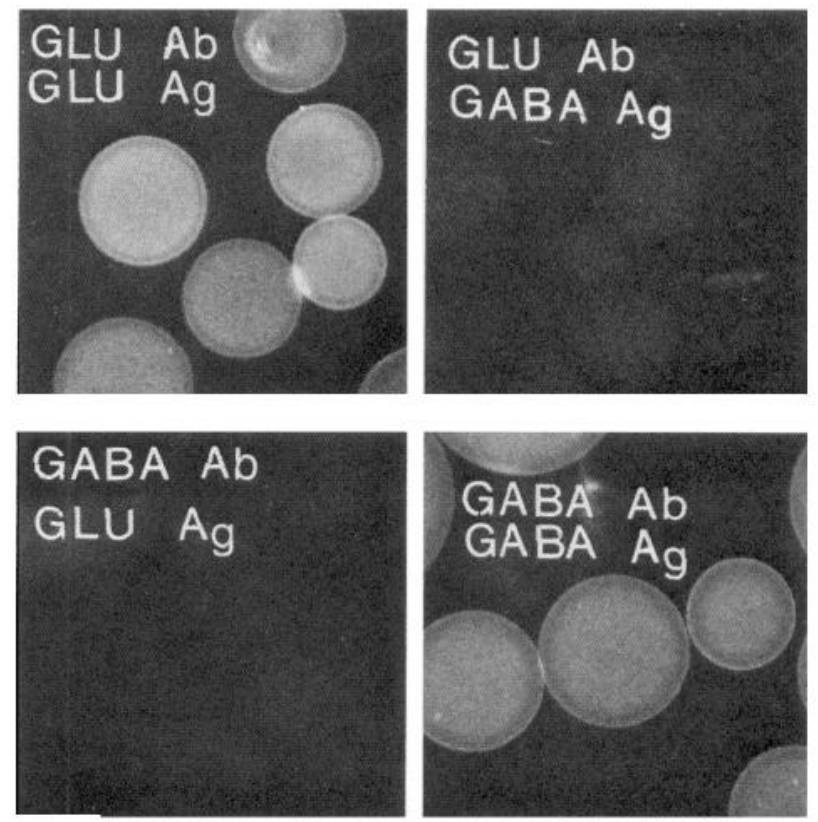

Figure 3. Glutamate $(G L U)$ or GABA antigens $(A g)$ were conjugated to Sepharose beads. Glutamate antisera $(A b)$ stained only the glutamateconjugated beads (top left) and did not stain the GABA-containing beads (top right). GABA antisera, on the other hand, stained only GABAcontaining beads, but not glutamate-containing beads.

in the physical developer eventually led to a random precipitation of different-sized silver particles over all tissue and nontissue areas of an ultrathin section.

\section{Discussion}

Glutamate as a hypothalamic transmitter. Although the finding of high levels of a suspected neurotransmitter antigen in presynaptic axon terminals does not by itself prove that the substance is released as a neurotransmitter, it is a necessary piece of evidence in this regard. That glutamate acts as a hypothalamic neurotransmitter in neuroendocrine circuits has received support from electrophysiological recordings. Application of glutamate to magnocellular neurons invariably causes an increase in the firing rate of stimulated neurons (Moss et al., 1972; Bioulac et al., 1978; Arnauld et al., 1983), similar to other neurons in the brain (Curtis and Johnston, 1974; Iversen, 1984). Broadspectrum excitatory amino acid antagonists such as kynurenic acid and gamma $d$-glutamylglycine block the action of the endogenous transmitter released by electrical stimulation of afferent projections to the supraoptic (Gribkoff and Dudek, 1988, 1990) and paraventricular nuclei (Wuarin and Dudek, 1988) and block most spontaneous excitatory postsynaptic potentials in these nuclei. Similarly, the non-NMDA glutamate receptor antagonist 6-cyano-7-dinitroquinoxaline-2,3-dione (CNQX) consistently blocked the majority of the excitatory response to electrical stimulation of the afferent axons projecting to the paraventricular and arcuate nuclei (van den Pol et al., 1990).

The data in the present study suggest glutamate as the primary candidate for the specific excitatory amino acid released by neuronal endings whose actions are blocked by general excitatory amino acid antagonists. Aspartate, localized in some hypothalamic axons, causes a smaller intracellular $\mathrm{Ca}^{2+}$ rise than does glutamate in many of the same cells tested. Cells cultured from 

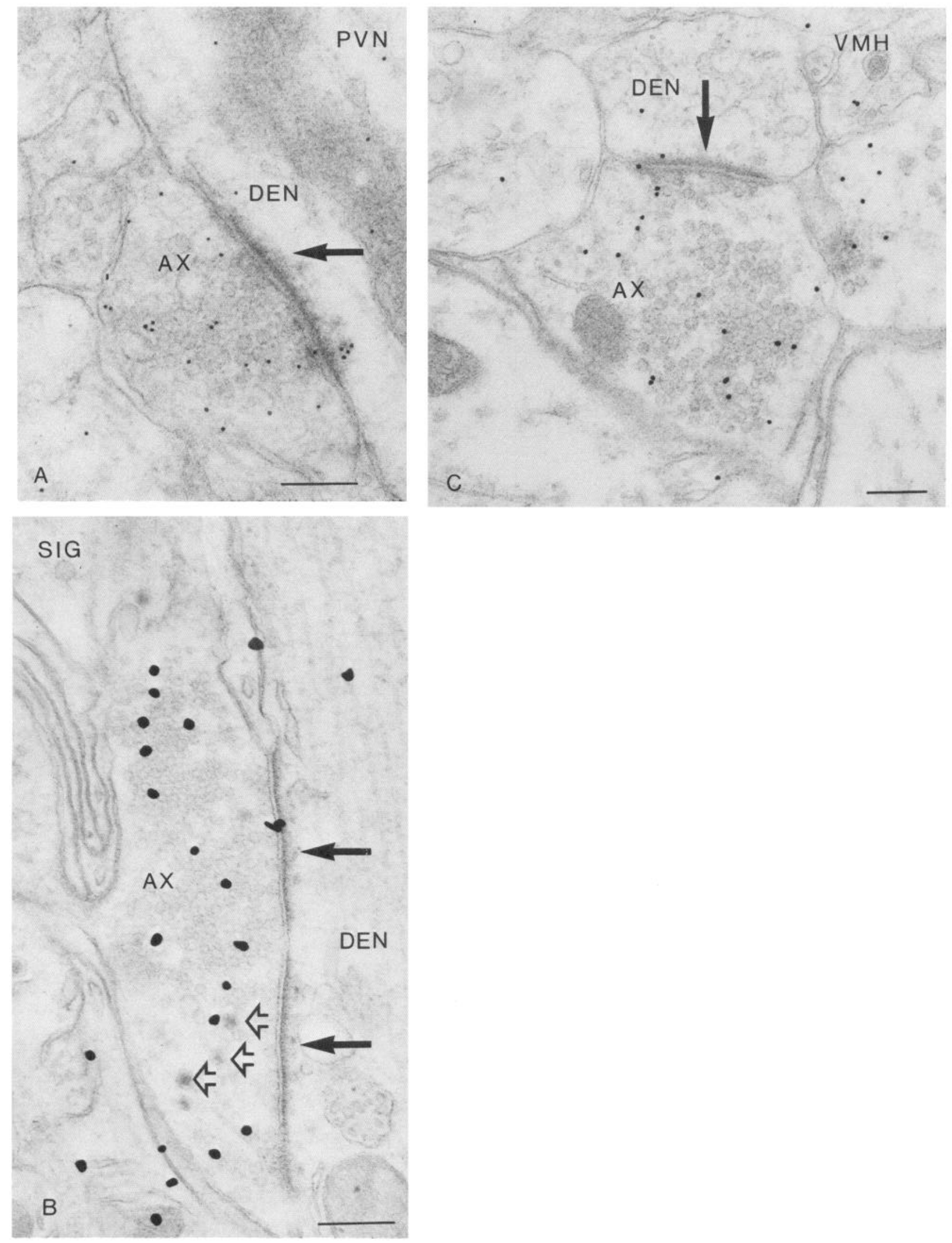

Figure 4. Glutamate immunoreactivity is found in the paraventricular nucleus $(P V N)$ in axon terminals. $A$, Round, clear vesicles are found in large numbers at the site of synaptic junction (arrow) in axons $(A X)$ immunolabeled for glutamate with 10-nm colloidal gold. These are presynaptic to dendrites $(D E N)$ with a much lower level of gold labeling. $B$, Silver-intensified gold $(S I G)$ particles label a PVN presynaptic axon that is immunoreactive for glutamate. Silver intensification makes the metallic particles an order of magnitude larger. Dense-core vesicles in glutamateimmunoreactive axons are noted by open arrows, synapse by solid arrow. $C$, Ventromedial nucleus $(V M H)$ glutamate immunoreactivity is shown by gold labeling of axon $(A X)$ that makes synaptic contact (arrow) with small dendrite. Scale bars: $A, 0.18 \mu \mathrm{m} ; B ; 0.22 \mu \mathrm{m} ; C, 0.19 \mu \mathrm{m}$. 

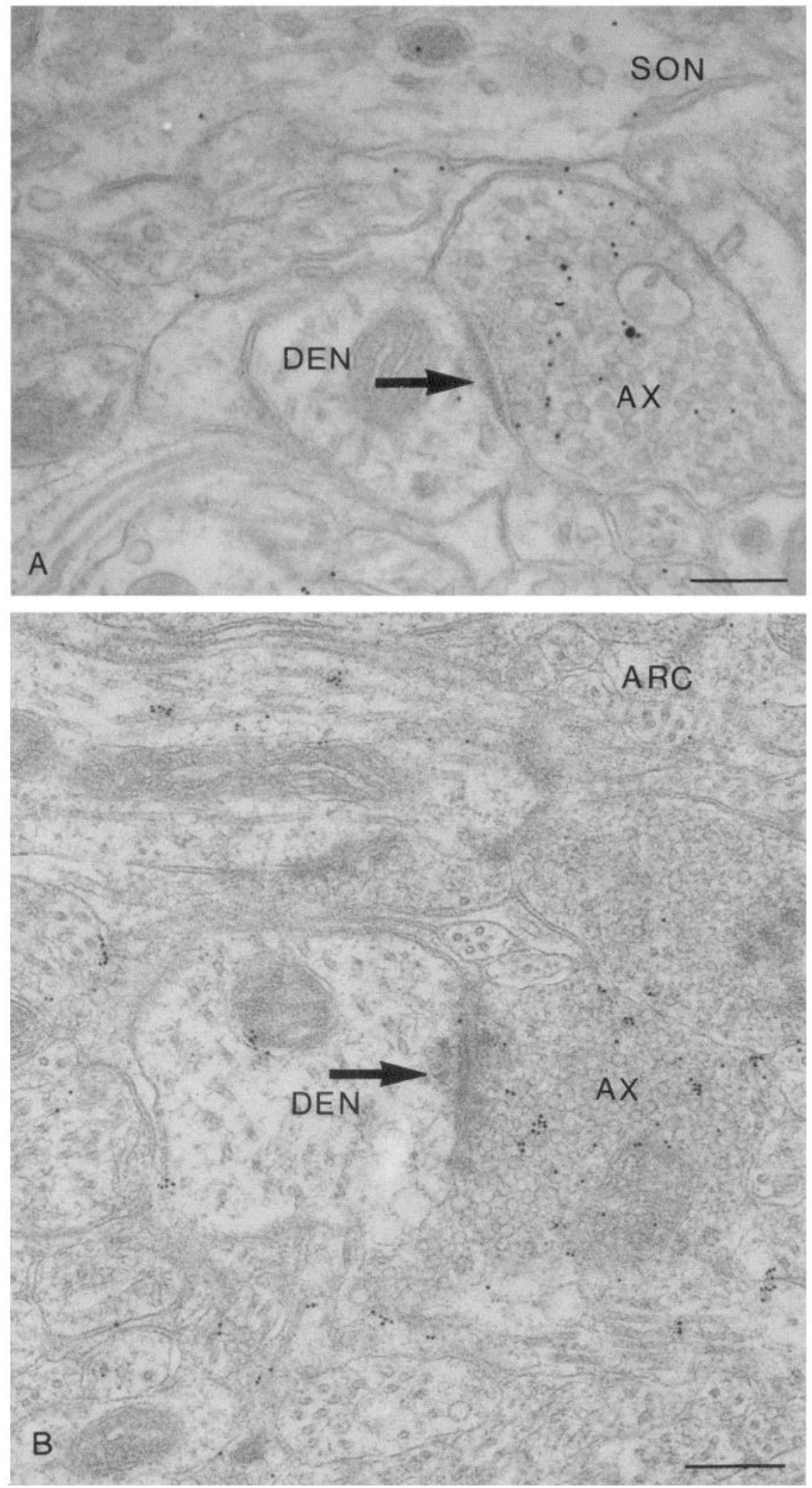

Figure 5. Supraoptic $(S O N ; A)$ and arcuate $(A R C ; B)$ nucleus glutamate immunoreactivity. Immunoreactive axons $(A X)$ exhibit a strong level of gold labeling compared with a postsynaptic dendrite $(D E N)$ in both the SON and the ARC. Synaptic specializations are indicated by arrows. Scale bars, $A, 0.14$ $\mu \mathrm{m} ; B, 0.20 \mu \mathrm{m}$. the mediobasal hypothalamus showed a heterogeneous group of responses to glutamate, aspartate, and NMDA. In a previous experiment, we found that almost all cells in culture responded to glutamate, kainate, and quisqualate, but only a minor response was seen to NMDA (van den Pol et al., 1990). By chang- ing several of the culture conditions, increasing the cell density, and eliminating extra glutamine, we found a more widespread response to NMDA. Exactly which factors may facilitate NMDA receptor expression is not clear; one of several possibilities is that the absence of glutamine, which can be converted to glu- 


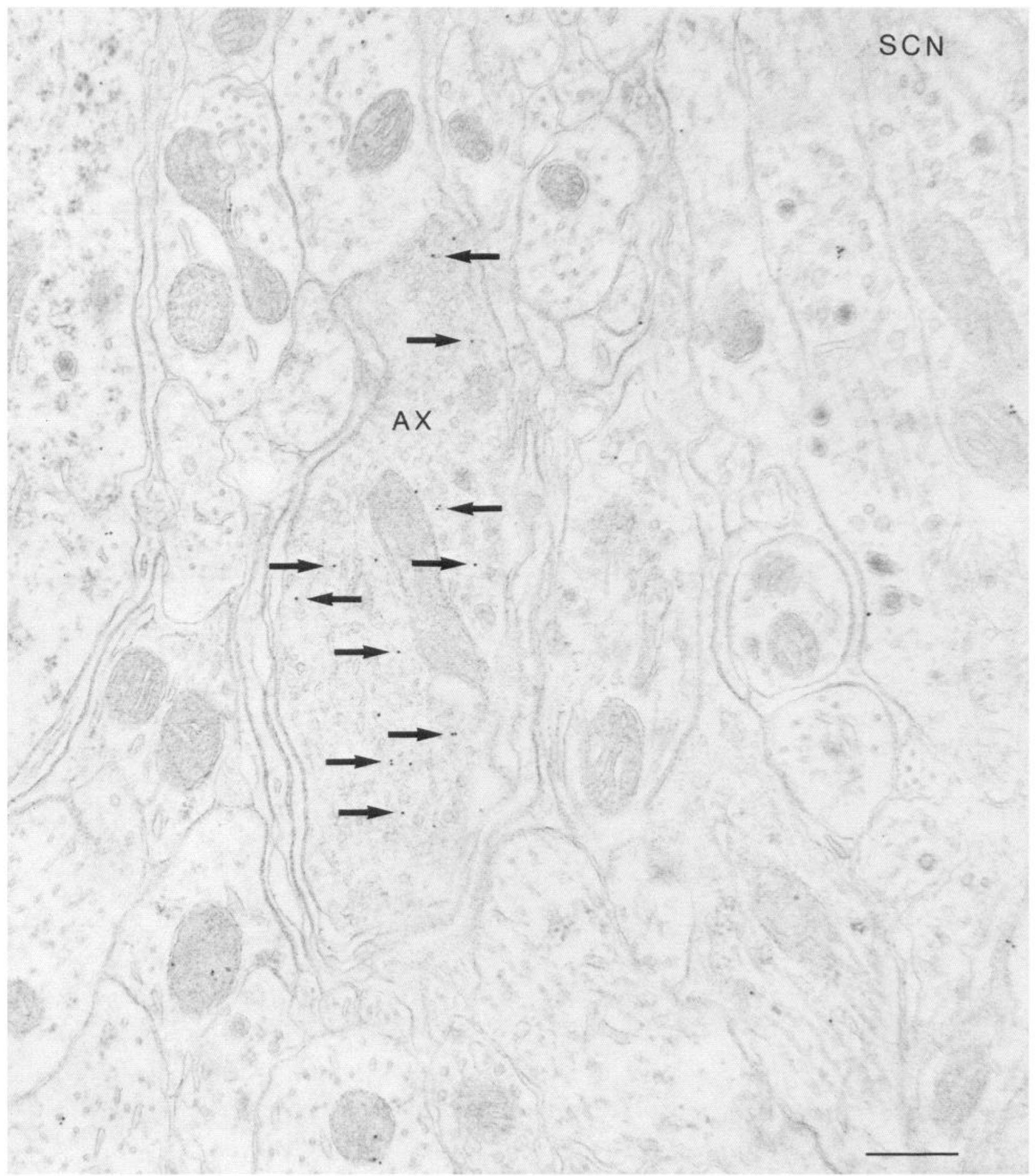

Figure 6. Suprachiasmatic nucleus $(S C N)$ axon $(A X)$. An axon in the $\mathrm{SCN}$ is heavily labeled with $10 \mathrm{~nm}$ gold particles (arrows). This photomicrograph is shown at low magnification to demonstrate the high immunoreactivity of this axon compared with the lower level of glutamate immunoreactivity found over the other axons, dendrites, and glial processes here. Scale bar, $0.24 \mu \mathrm{m}$.

tamate and thereby influence cell survival (Goldberg et al., 1988) and amino acid receptor expression, may have facilitated the increase in the NMDA response. Whether aspartate acts solely at the NMDA receptor (Patneau and Mayer, 1990) or at several receptor sites (Watkins and Evans, 1981) of hypothalamic neurons remains to be determined.

Substances that block the action of nonexcitatory amino acid neurotransmitters may alter the firing rate of hypothalamic neurons, but are relatively ineffective in blocking the actions of the endogenous transmitter released by electrical stimulation (Gribkoff and Dudek, 1990).

The source of glutamate-containing axons is unclear, but they probably arise from many loci. Some of the axons in the suprachiasmatic nucleus with high glutamate immunoreactivity 
may arise from the retina (Hendrickson et al., 1972; Moore and Lenn, 1972). Electrical stimulation of the optic nerve releases glutamate, but not GABA (Liou et al., 1986), and glutamate mimics the release of the retinal transmitter. The glutamate receptor antagonist kynurenic acid blocks the postsynaptic response to optic nerve stimulation as measured by field potentials (Shibata et al., 1986; Cahill and Menaker, 1987) and intracellular recording (Kim and Dudek, 1989). Behavioral experiments have shown that injections of glutamate into the suprachiasmatic nucleus, the putative site of the mammalian biological clock, cause a phase shift in activity cycles (Meijer et al., 1988).

That mediobasal hypothalamic neurons contain glutamate receptors is illustrated by experiments showing massive neuronal damage to cells and dendrites of the arcuate nucleus, but not to adjacent axons, after peripheral administration of monosodium glutamate to young rodents and primates (Olney and Sharpe, 1969; Olney et al., 1971). Damage to this region of the brain via the excitotoxic effects of large doses of glutamate occurs together with disturbances in the regulation of the endocrine system and caloric balances controlled by this region of the brain. Focal injections of excitatory neurotoxins including ibotenate and kainate have been reported to kill cells in the paraventricular nucleus, with some difference in toxicity among the different cell types (Zhang and Ciriello, 1985; Herman and Wiegand, 1986). That cells in some regions of the hypothalamus seem more resistant to neurotoxic glutamate analogs than cells elsewhere (Peterson and Moore, 1980; Hastings et al., 1985) may be due to different types of receptors, differences in secondmessenger systems, or different levels of ion channel activation. This resistance may also be due to fewer receptors, as shown by lower levels of receptor binding by glutamate agonists in the hypothalamus than in cortical areas (Monaghan and Cotman, 1982; Rainbow et al., 1984; Cotman et al., 1987). Evidence showing that a recently isolated novel glutamate receptor (GluR5) is expressed more strongly in the hypothalamus than in other areas of brain such as the hippocampus may explain some of the differences in response to glutamate (Bettler et al., 1990).

Immunocytochemical specificity. Because the amino end of glutamate is bound by glutaraldehyde, the antibody probably requires a free carboxy terminal to bind to. A different antibody against glutamate (Madl et al., 1986) can react with glutamate as part of the carboxy terminal of the tubulin protein, but not to tubulin lacking the glutamate at the carboxy terminal (McDonald et al., 1989).

When paraformaldehyde, a common fixative for microscopy, was substituted for glutaraldehyde with either immunodot blots or with the ELISA assay, the antibody used in the present study did not bind. This may have been due to paraformaldehyde not sufficiently cross-linking the glutamate to the protein matrix, and thus the glutamate was washed out. This is important in terms of the immunocytochemical localization in brain tissue. Most common fixatives for clectron microscopy employ combinations of paraformaldehyde and glutaraldehyde that result in excellent fixation (see references in Peters et al., 1976). How- ever, in the present case, where immunocytochemical localization of the glutamate is desired, paraformaldehyde would compete with glutaraldehyde for the available intracellular glutamate, and the paraformaldchydc-glutamate dimer would be subscquently washed out of the tissue. This is a particular problem hecause paraformaldehyde penetrates into tissue faster and is often used in an excess molarity compared with glutaraldehyde. Acrolein works better than paraformaldehyde, but still results in the loss of $97.5 \%$ of the signal. Because we found similar results with another antiserum against glycine conjugated by glutaraldehyde to thyroglobulin (van den Pol and Gorcs, 1988), one might expect most antibodies made against an amino acid conjugated by glutaraldehyde to a protein carrier molecule would react in a similar fashion, and therefore, caution should be exercised against using paraformaldehyde during tissue fixation if maximal amino acid antigen retention is important.

Cellular localization of glutamate immunoreactivity. An uneven distribution of a neurochemical is sometimes used as one criterion for its function as a neurotransmitter. When different brain rcgions are compared, a twofold difference in glutamate content can be detected (Curtis and Johnston, 1974). This uneven distribution is greatly magnified at the subcellular level, with presynaptic axons showing an average of three times and up to eight times more gold particles than dendrites postsynaptic to those axons. In comparison, hypothalamic axons immunoreactive for GABA had 10-20 times more gold particles over the presynaptic axon than over the postsynaptic dendrite (van den Pol, 1985, 1986a). The finding of different ratios of labeling is consistent with the role of glutamate both in neurotransmission and in metabolic activities including protein synthesis. GABA, on the other hand, which is not incorporated into proteins and does not have known significant roles other than neurotransmission, would be expected to have a higher ratio of labeling in immunoreactive axons compared to other elements of the neuropil. Glutamate immunoreactivity is high in axons of neural circuits known to be excitatory and postulated to use glutamate as a neurotransmitter. In the cerebellar cortex, excitatory terminals of mossy fibers and parallel fibers had higher levels of immunoreactivity than axon terminals from a known inhibitory cell, the Golgi cell (Somogyi et al., 1986). Similarly, in the hippocampus, mossy fibers that synapse on pyramidal cells have been postulated to use glutamate as a neurotransmitter (Storm-Mathisen et al., 1983). With the glutamate antiserum used in the present study, we confirmed the high level of glutamate in mossy fibers relative to other elements of the neuropil. The ratios of glutamate in some axons of the hypothalamic neuropil in the present study compare favorably with similar ratios found in excitatory axons of the cerebellum for which glutamate is the primary neurotransmitter candidate (Somogyi et al., 1986).

Asymmetrical synapses are often considered to be indicative of excitatory endings, while symmetrical synapses are thought to be inhibitory (see discussion in Peters et al., 1976). Data from the present study are in general agreement with this; however,

\footnotetext{
Figure 7. Dual staining with glutamate $(G L U)$ and $G A B A$ antisera. $A$, Large numbers of gold particles are found over an axon making an asymmetrical synaptic contact (solid arrow) and over a bouton not making synaptic contact (open arrow). $B$, The same axons are not labeled when GABA antiserum is substituted for glutamate antiserum. Arrows are same as in $A$. $C$, As a further control, on the same ultrathin section used in $B$, high densities of gold labcling immunoreactive GABA can be found over many axons making symmetrical synaptic contact (arrow). $D$, Glutamate staining of the same bouton from the same section as illustrated in $A$ shows fewer gold particles. Scale bar, $0.15 \mu \mathrm{m}$.
} 

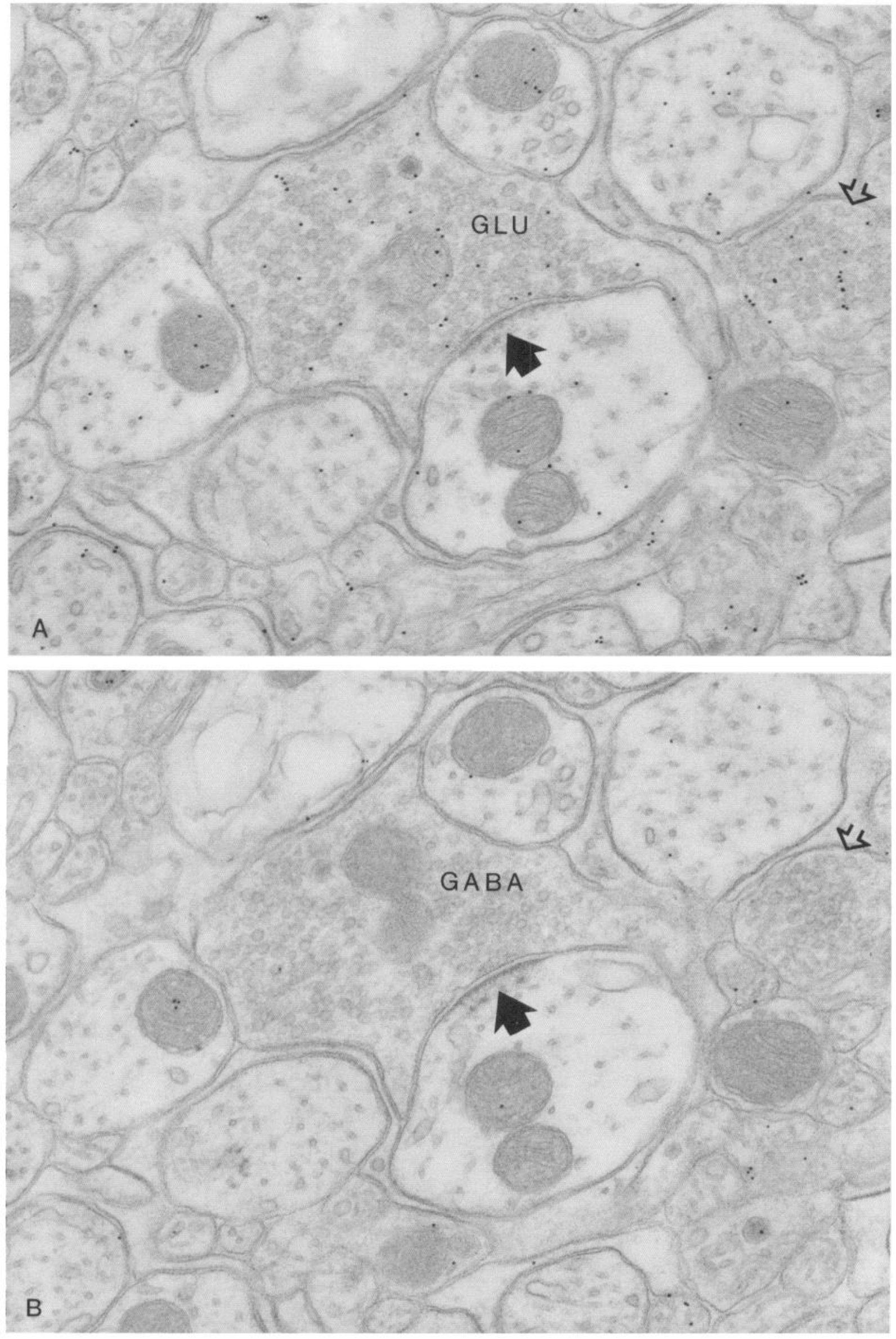

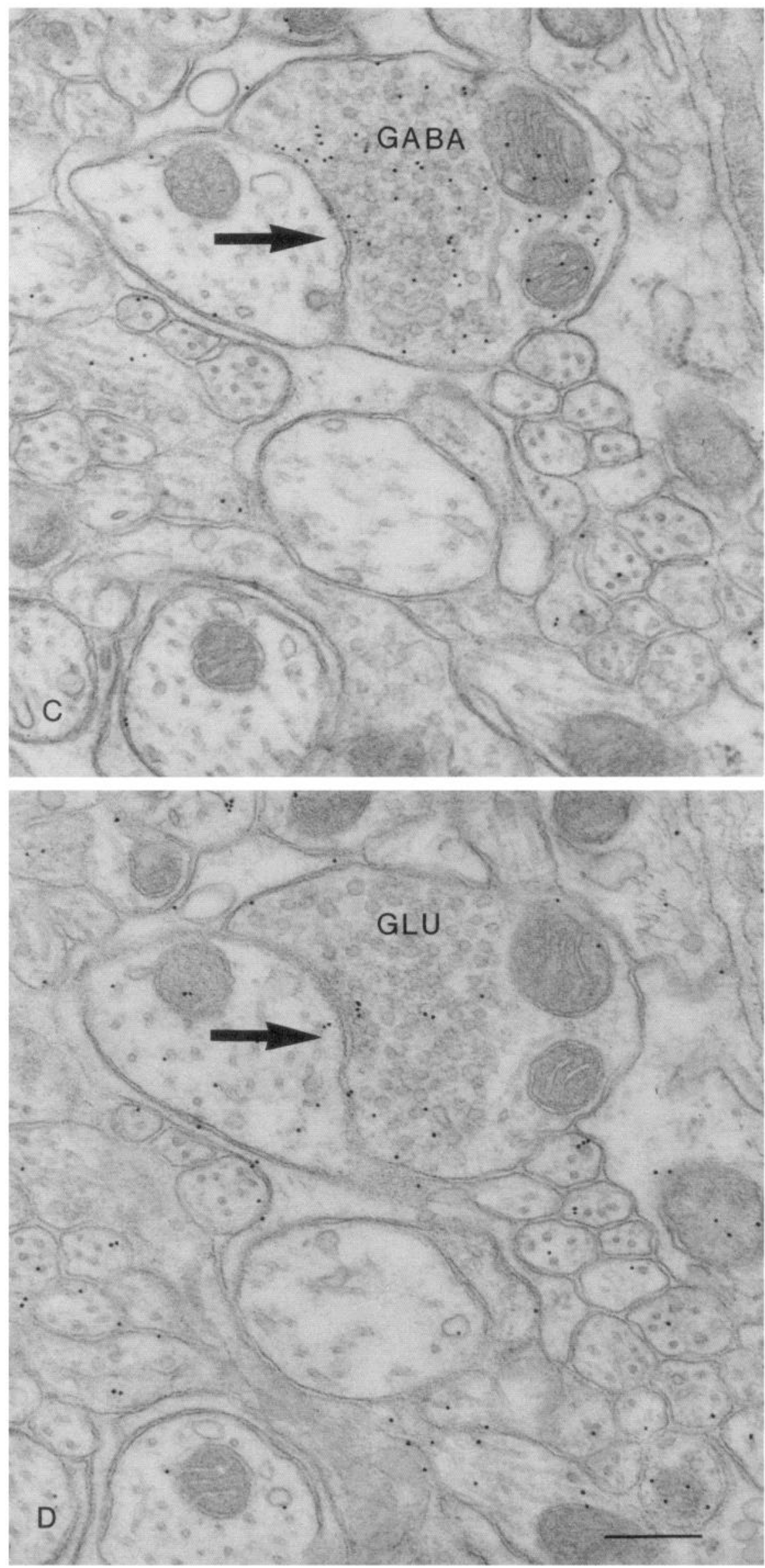


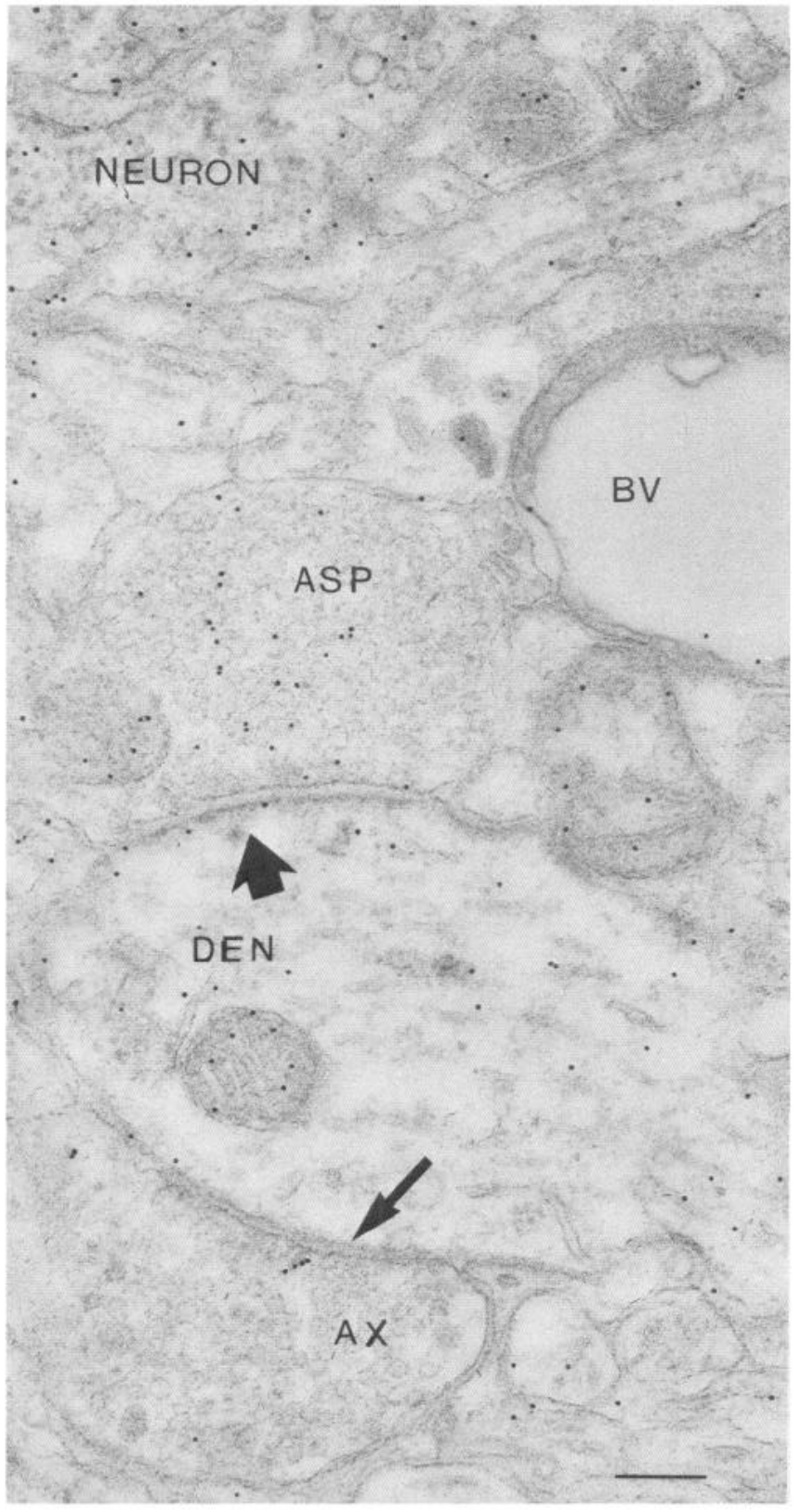

Figure 8. Aspartate $(A S P)$ immunoreactivity in the paraventricular nucleus. One axon $(A S P)$ makes an asymmetrical synapse on a dendrite $(D E N)$ that is slightly labeled. A second axon $(A X)$ shows little label. The lumen of the blood vessel $(B V)$ is almost clear of gold particles. At the top of the micrograph, the cell body of a magnocellular neuron is labeled $(N E U R O N)$. Scale bar, $150 \mathrm{~nm}$.

some presynaptic axons with strong glutamate immunoreactivity, and no GABA immunoreactivity, appeared to make symmetrical synapses. This could in part be due to the plane of the ultrathin section relative to the orientation of the synaptic cleft. However, we have also found a small percentage (1-3\%) of hypothalamic boutons strongly immunoreactive for GABA that make strikingly asymmetrical synaptic endings (Decavel and van den Pol, 1990). Together, these data would support the general probability of the inhibitory transmitter GABA being contained in boutons making symmetrical synapses and the excitatory transmitter glutamate in boutons making asymmet-
CALCIUM RESPONSE TO ASPARTATE, NMDA, GLUTAMATE

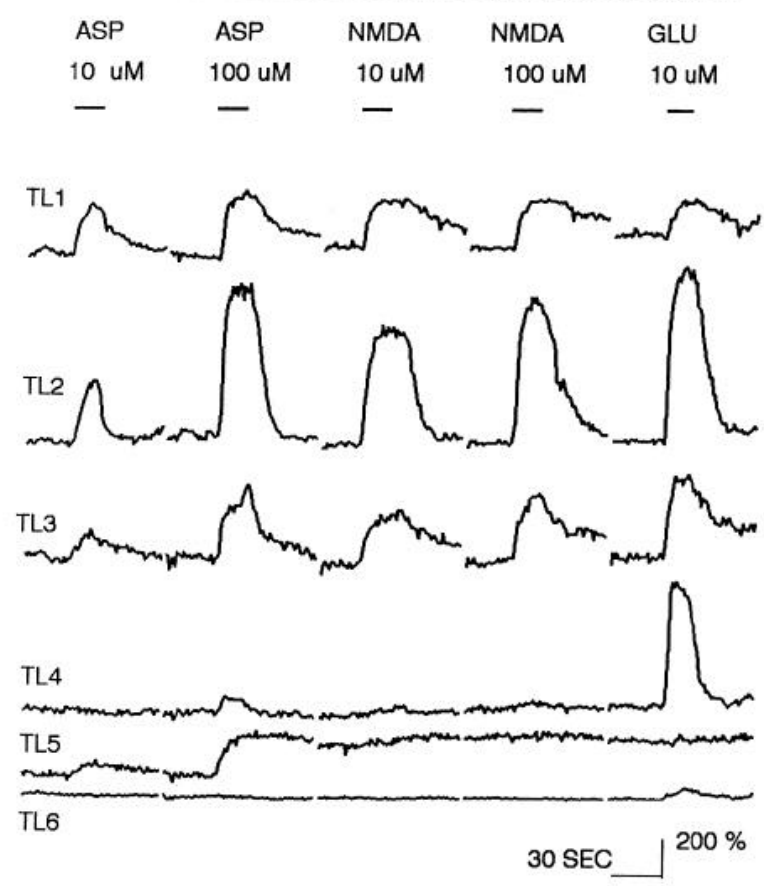

Figure 9. Recordings were made simultaneously from six hypothalamic cells $(T L 1-6)$ loaded with fluo-3. Recordings were normalized to the baseline fluorescence from each cell and are presented as a change in fluorescent intensity over baseline fluorescence $(\Delta F / F)$, allowing comparisons between cells from the same video field (Cornell-Bell et al., 1990). Each of the six cells was tested for $400 \mathrm{sec}$. For each application, recordings were made for $20 \mathrm{sec}$ prior to application, during $15 \mathrm{sec}$ of transmitter perfusion (shown by the lines at $t o p$ ) and for a 45 sec recovery period. To reduce possible phototoxicity and allow for a longer recovery period between transmitter application, an additional $60-\mathrm{sec}$ recovery period was used, during which the computer-controlled shutter allowing excitation from the mercury light was kept closed (shown by short gaps in the traces). Each trace represents the average of eight video frames. The shutter was closed during the part of the second when the video signal was not being averaged. A $1 \%$ transmittance neutral-density filter was used to reduce the intensity of the excitation light.

rical synapses, but also indicate that any single bouton in the hypothalamus cannot be classified as excitatory or inhibitory simply by its synaptic morphology.

Our finding of strong glutamate immunoreactivity in some axonal endings is consistent with some data showing high-affinity uptake of radiolabeled excitatory amino acids into axon terminals (Taxt and Storm-Mathisen, 1984). That the presence of glutamate in axons is not primarily due to its role in general metabolism is suggested by in vitro studies of hippocampal slices. After depletion of the metabolic pool of glutamate in neuronal cell bodies, the glutamate in axon terminals still showed a robust immunoreactivity (Ottersen and Storm-Mathisen, 1985); stimuli such as high potassium or veratridine in the presence of calcium, which depolarize neurons and induce release of neurotransmitters, caused a loss of axonal glutamate immunoreactivity (Cotman et al., 1987). In some regions of the brain, glia have been shown to take up glutamate (Ehinger and Falck, 1971). In the present study, glial processes had a much lower level of labeling than did neuronal processes in the same section. This indicates that, even with a high uptake mechanism in glia, the internal pool of glutamate is not as high in glia as in neurons. 


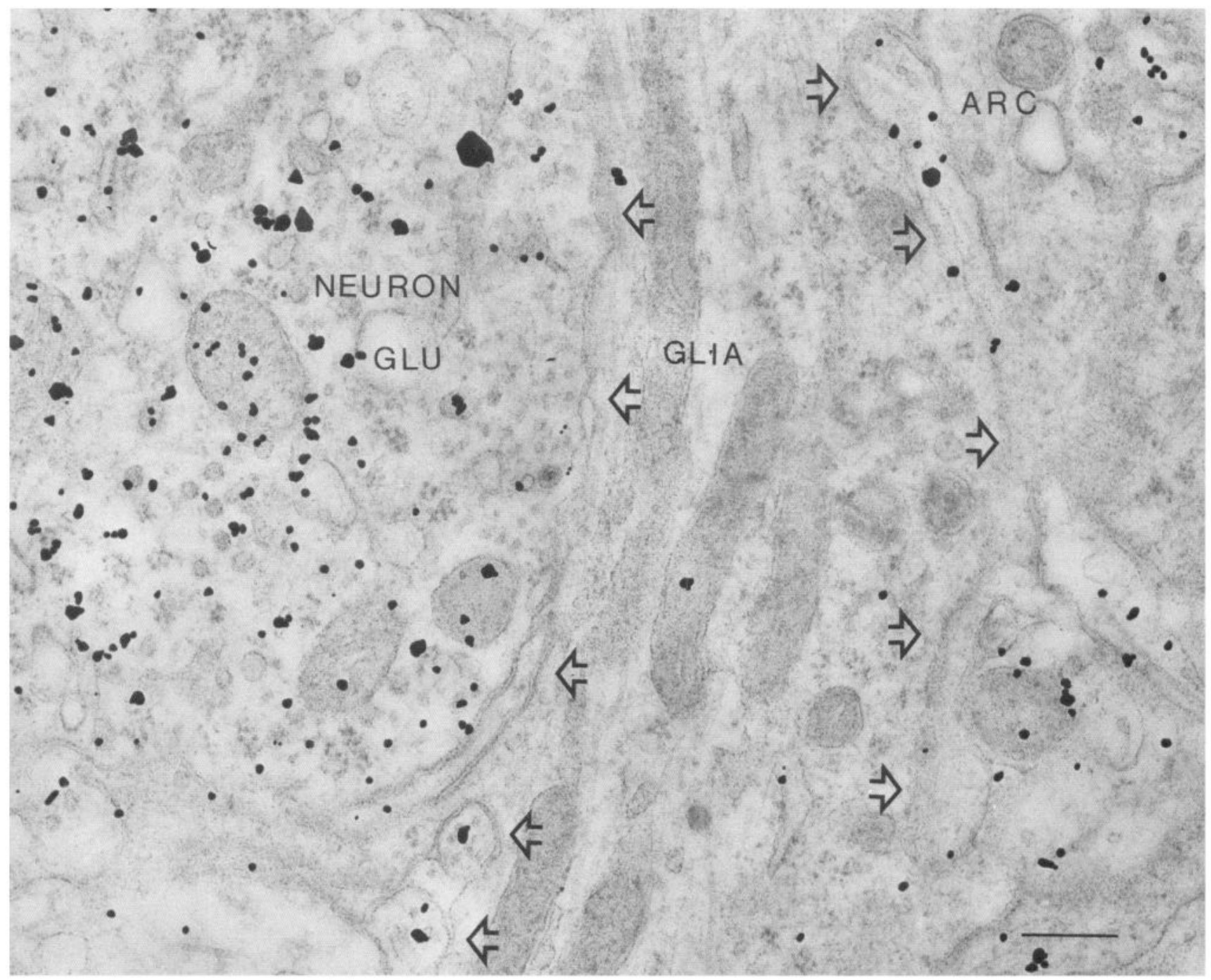

Figure 10. Neuron in the arcuate nucleus $(A R C)$ is heavily immunolabeled with glutamate antiserum $(G L U)$ and silver-intensified gold particles $($ NEURON), while in the adjacent glial cell $(G L I A)$, much less labeling is seen. The boundaries of the glial cell are shown with open arrows. Scale bar, $225 \mathrm{~nm}$.

As with the detection of other antigens with postembedding immunogold procedures (Somogyi and Hodgson, 1985; van den Pol, 1985; Somogyi et al., 1986; Ottersen, 1987), gold particles do not reveal all the antigens in a particular cell; however, the number of gold particles per unit area is roughly proportional to the total number of molecules (Ottersen, 1987). The absence of gold labeling in some elements of the neuropil does not necessarily indicate the absence of the amino acid. Rather, it indicates a relatively low level of glutamate in that particular cell compared with the high levels of glutamate in some axons. Had stronger concentrations of antibody or longer times of incubations been used, it is probable that more immunogold particles would be found over structures that might have less or no label with the procedures used in the present study.

Medium-size dense-core vesicles are found in many axon terminals that demonstrate a strong immunoreactivity for glutamate. Similarly, in hypothalamic axons that show high levels of GABA immunoreactivity, medium-size dense-core vesicles are invariably found in the same terminal (Decavel and van den
Pol, 1990). Because most evidence indicates that these densecore vesicles contain neuroactive peptides or proteins, the possibility exists that cells with axons that contain high levels of either GABA or glutamate routinely synthesize peptides or proteins that are transported to the axonal ending and probably released, suggesting that colocalization of peptides with amino acid transmitters may be the rule rather than the exception in the hypothalamus. Substance $\mathrm{P}$ has been identified as one peptide that is colocalized in a putative glutamatergic neuron of the dorsal root ganglion (Battaglia and Rustioni, 1988).

In conclusion, data from the present experiment, together with electrophysiological data revealing a widespread response to glutamate by hypothalamic neurons, the simulation of the effects of endogenous transmitter release by glutamate, the blockade of normal excitatory neurotransmission by glutamate receptor blockers, and the cytological data that hypothalamic neurons are susceptible to glutamate-like excitatory neurotoxins, support the hypothesis that excitatory amino acids, particularly glutamate, play a major role in excitatory neurotransmission throughout the hypothalamus. 


\section{References}

Arnauld E, Cirino M, Layton BS, Renaud LP (1983) Contrasting actions of amino acids, acetylcholine, noradrenaline, and leucine enkephalin on the excitability of supraoptic vasopressin-secreting neurons. Neuroendocrinology 36:187-196.

Atwood HL (1976) Organization and synaptic physiology of crustacean neuromuscular systems. Prog Neurobiol 7:291-391.

Battaglia G, Rustioni A (1988) Coexistence of glutamate and substance $P$ in dorsal root ganglion neurons of the rat and monkey. J Comp Neurol 277:302-312.

Bettler B, Boulter J, Hermans-Borgmeyer I, O'Shea-Greenfield A, Deneris ES, Moll C, Borgmeyer U, Hollman M, Heinemann S (1990) Cloning of a novel glutamate receptor subunit, GluR5: expression in the nervous system and during development. Neuron 5:583-595.

Bicker G, Schafer S, Ottersen OP, Storm-Mathisen J (1988) Glutamate-like immunoreactivity in identified neuronal populations of insect nervous systems. J Neurosci 8:2108-2122.

Bioulac B, Dufy B, DeVitry F, Fleury H, Tixier-Vidal A, Vincent JD (1978) Effects of acetylcholine, sodium glutamate, and GABA on the discharge of supraoptic neurons in the rat. Brain Res 154:159-162.

Cahill GM, Menaker M (1987) Kynurenic acid blocks suprachiasmatic nucleus responses to optic nerve stimulation. Brain Res 410:125-129.

Conti F, Rustioni A, Petrusz P, Towle AC (1987) Glutamate-positive neurons in the somatic sensory cortex of rats and monkeys. J Neurosci 7:1887-1901.

Cornell-Bell AH, Finkbeiner SM, Cooper MS, Smith SJ (1990) Glutamate induces calcium waves in cultured astrocytes: long-range glial signaling. Sciénce 247:470-473.

Cotman CW, Monaghan DT, Ottersen OP, Storm-Mathisen J (1987) Anatomical organization of excitatory amino acid receptors and their pathways. Trends Neurosci 10:273-280.

Curtis DR, Johnston GAR (1974) Amino acid transmitters in the mammalian central nervous system. Ergeb Physiol 69:97-189.

Danscher G (1981) Histochemical demonstration of heavy metals. A revised version of the sulphide silver method suitable for both light and electronmicroscopy. Histochemistry 71:1-16.

De Belleroche JS, Bradford HF (1972) Metabolism of beds of mammalian cortical synaptosomes: response to depolarizing influences. J Neurochem 19:585-602.

Decavel C, van den Pol AN (1990) GABA: a dominant transmitter in the hypothalamus. J Comp Neurol 302:1019-1037.

Ehinger B, Falck B (1971) Autoradiography of some suspected neurotransmitter substances: GABA, glycine, glutamic acid, histamine, dopamine, and L-dopa. Brain Res 33:157-172.

Ganong WF, Martini L (1990) Neuroendocrinology, 1990. Front Neuroendocrinol 11:1-5.

Goldberg MP, Monyer H, Choi DW (1988) Hypoxic neuronal injury in vitro depends on extracellular glutamine. Neurosci Lett 94:52-57.

Gribkoff VK, Dudek FE (1988) The effects of the excitatory amino acid antagonist kynurentic acid on synaptic transmission to supraoptic neuroendocrine cells. Brain Res 442:152-156.

Gribkoff VK, Dudek FE (1990) The effects of excitatory amino acid antagonists on synaptic responses of supraoptic neurons in slices of rat hypothalamus. J Neurophysiol 63:60-71.

Hastings MH, Winn P, Dunnett SB (1985) Neurotoxic amino acid lesions of the lateral hypothalamus: a parametric comparison of the effects of ibotenate, $N$-methyl-D.L-aspartate and quisqualate in the rat. Brain Res 360:248-256.

Hendrickson AE, Wagoner N, Cowan WM (1972) An autoradiographic and electron microscopic study of retino-hypothalamic connections. Z Zellforsch 135:1-26.

Herman JP, Wiegand SJ (1986) Ibotenate-induced cell death in the hypothalamic paraventricular nucleus: differential susceptibility of magnocellular and parvicellular neurons. Brain Res 383:367-372.

Hodgson AJ, Penke B, Erdei A, Chubb IW, Somogyi P (1985) Antisera to gamma amino butyric acid. I. Production and characterization using a new model system. J Histochem Cytochem 33:229-239.

Hokfelt T, Elde R, Fuxe K, Johansson O, Ljungdahl A, Goldstein M, Luft R, Efendic S, Nilsson G, Terenius L, Ganten D, Jeffcoate SL, Rehfield J, Said S, Perez de la Mora M, Possani L, Tapia R, Teran L, Palacios R (1978) Aminergic and peptidergic pathways in the nervous system with special reference to the hypothalamus. In: The hypothalamus (Recihlin S, Balderssarini RJ, Martin JB, eds), pp 69135. New York: Raven.
Holgate CS, Jackson P, Cowen PN, Bird CC (1983) Immunogoldsilver staining: new method of immunostaining with enhanced sensitivity. J Histochem Cytochem 31:938-944.

Hsu S, Raine L, Fanger H (1981) Use of avidin-biotin-peroxidase complex $(A B C)$ in immunoperoxidase techniques: a comparison between $\mathrm{ABC}$ and unlabeled antibody (PAP) procedures. J Histochem Cytochem 29:577-580.

Iversen LL (1984) Amino acids and peptides, fast and slow chemical signals in the nervous system? Proc R Soc Lond [Biol] 221:245-260.

Kim YI, Dudek FE (1989) Antagonism of fast excitatory postsynaptic potentials in suprachiasmatic nucleus neurons by excitatory amino acid antagonists. Soc Neurosci Abstr 15:1088.

Liesegang R (1911) Die Kolloidchemie der histologischen Silberfarbungen. Kolloid Beihefte 3:1-46.

Liou SY, Shibata S, Iwasaki K, Ueki S (1986) Optic nerve stimulationinduced increase of release of ${ }^{3} \mathrm{H}$-glutamate and ${ }^{3} \mathrm{H}$-aspartate but not ${ }^{3} \mathrm{H}-\mathrm{GABA}$ from the suprachiasmatic nucleus in slices of rat hypothalamus. Brain Res Bull 16:527-531.

Madl JE, Larson AA, Beitz AJ (1986) Monoclonal antibody specific for carbodiimide-fixed glutamate: immunocytochemical localization in the rat CNS. J Histochem Cytochem 34:317-326.

McDonald AJ, Beitz AJ, Larson AA, Kuriyama R, Sellitto C, Madl JE (1989) Co-localization of glutamate and tubulin in putative excitatory neurons of the hippocampus and amygdala: an immunohistochemical study using monoclonal antibodies. Neuroscience 30:405421.

Meeker RB, Swanson DJ, Hayward JN (1989) Light and electron microscopic localization of glutamate immunoreactivity in the supraoptic nucleus of the rat hypothalamus. Neuroscience 33:157-167.

Meijer JH, van der Zee EA, Dietz M (1988) Glutamate phase shifts circadian activity in hamsters. Neurosci Lett 86:177-183.

Monaghan DT, Cotman CW (1982) The distribution of $\left[{ }^{3} \mathrm{H}\right]$ kainic acid biding sites in rat CNS as determined by autoradiography. Brain Res 252:91-100.

Moore RY, Lenn NJ (1972) A retinohypothalamic projection in the rat. J Comp Neurol 146:1-14.

Moss RL, Urban I, Cross BA (1972) Microelectrophoresis of cholinergic and aminergic drugs on paraventricular neurons. Am J Physiol 223:310-318.

Mulder AH, Snyder SH (1974) Potassium-induced release of amino acids from cerebral cortex and spinal cord slices of the rat. Brain Res 76:297-308.

Nicholls DG, Sihra TS (1986) Synaptosomes possess an exocytotic pool of glutamate. Nature 321:772-774.

Olney JW, Sharpe LG (1969) Brain lesions in an infant rhesus monkey treated with monosodium glutamate. Science 166:386-388.

Olney JW, Ho OL, Rhee V (1971) Cytotoxic effects of acidic and sulfur containing amino acids on the infant mouse central nervous system. Exp Brain Res 14:61-70.

Ottersen OP (1987) Postembedding light- and electron microscopic immunocytochemistry of amino acids: description of a new model system allowing identical conditions for specificity testing and tissue processing. Exp Brain Res 69:167-174.

Ottersen OP (1989) Quantitative electron microscopic immunocytochemistry of neuroactive amino acids. Anat Embryol 180:1-15.

Ottersen OP, Storm-Mathisen J (1984) Glutamate- and GABA-containing neurons in the mouse and rat brain, as demonstrated with a new immunocytochemical technique. J Comp Neurol 229:374-392.

Ottersen OP, Storm-Mathisen J (1985) Different neuronal localization of aspartate-like and glutamate-like immunoreactivities in the hippocampus of rat, guinea-pig and senegalese baboon (Papio papio), with a note on the distribution of gamma-aminobutyrate. Neuroscience 16:589-606.

Patneau DK, Mayer ML (1990) Structure-activity relationships for amino acid transmitter candidates acting at $N$-methyl-D-aspartate and quisqualate receptors. J Neurosci 10:2385-2399.

Peters A, Palay SL, Webster H (1976) Fine structure of the nervous system, pp 1-406. Philadelphia: Saunders.

Peterson GM, Moore RY (1980) Selective effects of kainic acid on diencephalic neurons. Brain Res 202:165-182.

Poulain DA, Wakerley JB (1982) Electrophysiology of hypothalamic magnocellular neurons secreting oxytocin and vasopressin. Neuroscience 4:773-808.

Rainbow TC, Wieczorek CM, Halpain S (1984) Quantitative autoradiography of binding sites for [ $\left.{ }^{3} \mathrm{H}\right] \mathrm{AMPA}$, a structural analogue of glutamic acid. Brain Res 309:173-177. 
Renaud LP (1987) Magnocellular neuroendocrine neurons: update on intrinsic properties, synaptic inputs and neuropharmacology. Trends Neurosci 10:498-502.

Renaud LP, Bourque CW, Day TA, Ferguson AV, Randle JC (1985) Electrophysiology of mammalian hypothalamic supraoptic and paraventricular neurosecretory cells. In: The electrophysiology of the secretory cell (Poisner AM, Trifaro J, eds), pp 165-194. Amsterdam: Elsevier.

Shibata S, Liou SY, Ueki S (1986) Influence of excitatory amino acid receptor antagonists and of baclofen on synaptic transmission in the optic nerve to the suprachiasmatic nucleus in slices of rat hypothalamus. Neuropharmacology 25:403-409.

Silverman JA, Pickard GE (1983) The hypothalamus. In: Chemical neuroanatomy (Emson PC, ed), pp 295-336. New York: Raven.

Sladek CD, Armstrong WE (1987) Effect of neurotransmitters and neuropeptides on vasopressin release. In: Vasopressin (Gash DM, Boer GJ, eds), pp 275-333. New York: Plenum.

Somogyi P, Hodgson AJ (1985) Antiserum to gamma amino butyric acid. III. Dcmonstration of GABA in Golgi-impregnated ncurons and in conventional electron microscopic sections of cat striate cortex. $J$ Histochem Cytochem 33:249-257.

Somogyi P, Halasy K, Somogyi J, Storm-Mathisen J, Ottersen OP (1986) Quantification of immunogold labelling reveals enrichment of glutamate in mossy and parallel fibre terminals in cat cerebellum. Neuroscience 19:1045-1050.

Sternberger LA (1986) Immunocytochemistry. New York: Wiley.

Storm-Mathisen J, Leknes AK, Bore AT, Vaaland JL, Edminson P. Haug FM, Ottersen OP (1983) First visualization of glutamate and GABA in neurones by immunocytochemistry. Nature 301:517-520.

Swanson LW (1987) The hypothalamus. In: Handbook of chemical neuroanatomy. Integrated systems of the CNS, Pt 1, Hypothalamus, hippocampus, amygdala, retina (Bjorklund A, Hokfelt T, Swanson LW, eds), pp 1-124. Amsterdam: Elsevier.

Swanson LW, Sawchenko PE (1983) Hypothalamic integration: organization of the paraventricular and supraoptic nuclei. Annu Rev Neurosci 6:269-324.

Taxt T, Storm-Mathisen J (1984) Uptake of D-asparate and L-glutamate in excitatory axon terminals in hippocampus: autoradiographic and biochemical comparison with gamma-aminobutyrate and other amino acids in normal rats and in rats with lesions. Neuroscience 11 : 79-100. van den Pol AN (1984) Colloidal gold and biotin-avidin conjugates as ultrastructural markers for neural antigens. Quart J Exp Physiol 69:1-33.

van den Pol AN (1985) Dual ultrastructural localization of two neurotransmitter-related antigens: colloidal gold labeled neurophysin immunoreactive supraoptic neurons receive peroxidase labeled glutamate decarboxylase or gold labeled GABA immunoreactive synapses. J Neurosci 5:2940-2954.

van den Pol AN (1986a) Gamma-aminobutyrate, gastrin releasing peptide, serotonin, somatostatin, and vasopressin: ultrastructural immunocytochemical localization in presynaptic axons in the suprachiasmatic nucleus. Neuroscience 17:643-659.

van den Pol AN (1986b) Tyrosine hydroxylase immunoreactive neurons throughout the hypothalamus receive glutamate decarboxylase immunoreactive synapses: a double pre-embedding immunocytochemical study with particulate silver and HRP. J Neurosci 6:877891.

van den Pol AN (1989) Neuronal imaging with colloidal gold. J Microsc 155:27-59.

van den Pol AN, Decavel C (1990) Synaptic interaction between chemically defined neurons: dual ultrastructural immunocytochemical approaches. In: Methods for the analysis of neuronal microcircuits and synaptic interactions (Bjorklund A, Hokfelt T, Wouterlood F, van den Pol AN, eds), pp 199-272. Amsterdam: Elsevier.

van den Pol AN, Gorcs T (1988) Glycine and glycine receptor immunoreactivity in brain and spinal cord. J Neurosci 8:472-492.

van den Pol AN, Wuarin JP, Dudek FE (1990) Glutamate, the dominant excitatory transmitter in neuroendocrine regulation. Science 250:1276-1278.

Vargas O, de Lorenzo CD, Orrego F (1977) Effects of elevated extracellular potassium on the release of labelled noradrenaline, glutamate, glycine, $\beta$-alanine and other amino acids from rat brain cortex slices. Ncurosciencc 2:383-390.

Watkins JC, Evans RH (1981) Excitatory amino acid transmitters. Annu Rev Pharmacol Toxicol 21:165-204.

Wuarin JP, Dudek FE (1988) Kynurenate antagonism of fast EPSP's in paraventricular neurons. Soc Neurosci Abstr 14:1178.

Zhang T-X, Ciriello J (1985) Kainic acid lesions of paraventricular nucleus neurons reverse the elevated arterial pressure after aortic baroreceptor denervation in the rat. Brain Res 358:334-338. 